\title{
PRÁTICAS DE ALFABETIZAÇÃO COM CRIANÇAS DE SEIS ANOS NO ENSINO FUNDAMENTAL: DIFERENTES ESTRATÉGIAS, DIFERENTES CONCEPÇÕES
}

\author{
Maria do Socorro Alencar Nunes Macedo ${ }^{I}$ \\ Ana Caroline de Almeida ${ }^{I}$ \\ Ana Paula do Amaral Tiburcio ${ }^{2}$
}

\begin{abstract}
RESUMO: Este artigo tem o objetivo de apresentar e discutir duas práticas de alfabetização com crianças de seis anos, no contexto da ampliação do tempo no Ensino Fundamental. A perspectiva etnográfica dos Novos Estudos do Letramento configurou-se como principal aporte teórico metodológico. Questionandonos sobre qual seria o ponto de partida escolhido pelas docentes para o ensino da leitura e da escrita, vislumbramos duas práticas distintas de alfabetização: uma, cujo ponto de partida para a construção dos eventos de letramento era uma determinada letra do alfabeto; e outra, que teve predominantemente o texto e o contexto como disparadores desse processo.
\end{abstract}

Palavras-chave: Ensino Fundamental. Alfabetização. Sala de aula. Etnografia.

\footnotetext{
${ }^{1}$ Universidade Federal de Pernambuco, Programa de Pós-Graduação em Educação - Recife (PE), Brasil. E-mails: karolyne_jv@yahoo.com.br, socorronunesmacedoufsj@gmail.com ${ }^{2}$ Universidade Federal de São João del-Rei, Programa de Pós-Graduação em Educação São João del-Rei (MG), Brasil. E-mail: anapaulajfmg@yahoo.com.br

DOI: 10.1590/CC0101-32622017173622
} 


\title{
Literacy practices with six-year-olds in elementary school: different strategies, different conceptions
}

\begin{abstract}
This article aims to present and discuss two literacy practices with children six years old in the context of the extension of the time in elementary school. The ethnographic perspective of the New Literacy Studies was configured as main methodological and theoretical support. Questioning about what was the starting point chosen by teachers for teaching reading and writing we contrasted two different literacy practices: one, whose starting point for the construction of literacy events was each letter of the alphabet; and another, who had predominantly text and context as triggers this process.
\end{abstract}

Keywords: Elementary school. Literacy. Classroom. Etnography.

\section{INTRODUÇÃO}

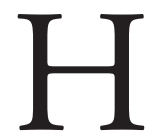

á 10 anos, o cenário educacional brasileiro foi consideravelmente impactado a partir de uma mudança legal - Lei no 11.274 (BRASIL, 2006), que alterou a estrutura e a organização da escolarização básica no país. Essa mudança inseriu as crianças com seis anos de idade, faixa etária que até então integrava a etapa da Educação Infantil (EI), no primeiro ano do Ensino Fundamental (EF), ampliando o tempo de duração desta etapa de 8 para 9 anos.

Como pesquisadoras do campo da alfabetização e do letramento em escolas públicas de Minas Gerais, interessou-nos compreender como aconteciam as práticas de leitura e escrita com as crianças de seis anos no EF. Questionamos: qual é a concepção de alfabetização subjacente a essas práticas? Quais eram os recursos pedagógicos utilizados nas salas de aula do $1^{\circ}$ ano? Como esses recursos eram utilizados? Qual é o papel do livro didático e/ou de outros impressos nesse contexto? Como os textos eram explorados no trabalho com a alfabetização? 


\section{PERSPECTIVA TEÓRICO-METODOLÓGICA}

Para buscar respostas aos nossos questionamentos, adotamos os pressupostos da pesquisa de cunho etnográfico como principal aporte teórico-metodológico. Tal abordagem busca compreender a sala de aula como uma comunidade culturalmente constituída. Dialogamos, portanto, com os estudos de Green, Dixon e Zaharlich (2005), Ezpeleta e Rockwell (1986); Rockwell (2009), Castanheira et al. (2007), Macedo (2005) Street e Heath (2008), dentre outros.

Green, Dixon e Zaharlich (2005) defendem que já existe um conjunto considerável de pesquisas na interface entre etnografia e educação, além de conceitos, práticas e açôes, as quais possibilitam entender a etnografia como uma abordagem de pesquisa para o campo da educação. Nessa abordagem, existem pressupostos que nos ajudam a compreender os padróes culturais e as práticas da vida cotidiana, dar visibilidade aos princípios de práticas comumente invisíveis que norteiam as ações, interações, produção de artefatos e construção de eventos e atividades da vida diária dos membros de um grupo e entender as relaçóes entre parte-todo. De acordo com Ezpeleta e Rockwell (1986), em uma pesquisa etnográfica, o que o etnógrafo busca é "documentar o não documentado", observando tudo o que acontece e não apenas os aspectos que se relacionam especificamente ao seu tema de pesquisa.

Neste texto, apresentamos os resultados obtidos em duas pesquisas realizadas em Minas Gerais. A primeira desenvolveu-se em 2010, na rede municipal de ensino de Tiradentes, com a observação de 47 dias, entre abril e novembro. E a segunda ocorreu, em 2013, na rede municipal de Juiz de Fora, com a observação de 45 dias ao longo do primeiro semestre letivo. Nosso objetivo é contrastar estes dois estudos, utilizando-nos do contraste como uma estratégia de análise, conforme realizado por Macedo (2005).

Durante as observaçóes, tomamos notas, realizamos algumas gravaçóes de aulas em áudio e vídeo, e fizemos entrevistas com as professoras das turmas. Além disso, recolhemos algumas atividades impressas, realizadas pelas crianças. Mesmo o foco sendo a sala de aula, não nos limitamos a observar apenas esse espaço, mas todo o contexto do qual as crianças participavam. 
Buscamos compreender os significados da leitura e da escrita para os sujeitos das turmas que observamos, compreendendo as práticas de alfabetização e letramento como um fenômeno sociocultural (STREET, 1984). Assim, consideramos a observação como um encontro de múltiplas vozes, em uma perspectiva discursiva, dialógica e polifônica, entendendo, por meio da teoria enunciativa da linguagem proposta por Bakhtin (1995), que o campo nos propóe variados eventos de linguagem marcados pela interlocução que aí se estabelece.

\section{RESULTADOS}

\section{ESCOLA 1: A LETRA DO ALFABETO COMO PONTO DE PARTIDA PARA O ENSINO DA LEITURA E DA ESCRITA}

A escola de Tiradentes, doravante escola 1, funcionava em dois turnos, atendendo a crianças da EI e do EF. O turno da manhã acolhia as turmas de $4^{\circ}$ e $5^{\circ}$ anos, em regime seriado, e o turno da tarde, os $1^{\circ} \mathrm{e}$ $2^{\circ}$ períodos da EI (crianças de 4 e 5 anos) e das turmas do Ciclo Inicial

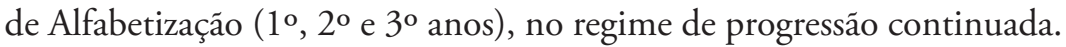
A escola atendia, nessa época, cerca de 300 alunos, sendo apenas uma turma de $1^{\circ}$ ano.

Esta turma ocupava uma sala enfeitada com um painel e cartazes, no qual se observava o nome dos alunos, regras de boas maneiras, as condições climáticas e os ajudantes do dia, além do alfabeto e dos numerais. No alfabeto, viam-se as quatro formas da letra (maiúscula, minúscula, cursiva e impressa), uma figura e uma palavra. Os numerais, pendurados em cartelas de 0 a 9, apresentavam o número e a quantidade. Na sala, havia um "cantinho de leitura", com alguns livros antigos de literatura infantil, que não foram utilizados pela professora durante a coleta de dados; armário para a professora; e 23 carteiras em tamanho inadequado para as crianças e dispostas em cinco filas quase que cotidianamente.

Durante as observaçóes, acompanhamos as aulas de todas as disciplinas, mas as aulas de Língua Portuguesa foram centrais para a nossa pesquisa, uma vez que o processo de ensino e aprendizagem da leitura 
e da escrita acontecia predominantemente nessas aulas. Esse processo era organizado por uma sequência de atividades mimeografadas para cada letra do alfabeto, com o objetivo explícito de levar as crianças à compreensão do sistema de escrita. Essas atividades eram retiradas de coleçóes para a alfabetização compradas pela professora.

A primeira folha que as crianças recebiam, ou o primeiro passo nesse processo, era "apresentar" uma letra do alfabeto. $\mathrm{Na}$ folha, a criança via a letra em questão, nas quatro formas que ela pode assumir no nosso cotidiano: uma figura, cujo nome começasse com tal letra; e um texto bastante curto e acartilhado. A cada nova letra apresentada, a professora retomava a sequência do alfabeto e chegava-se à letra em questáo. Alunos e professora iam compondo a família silábica daquela letra. A professora costumava, ainda, pedir para as crianças identificarem e circularem no texto a letra que estava sendo apresentada e, por fim, deixava-as pintarem a figura.

Esse primeiro passo do processo é reforçado pela professora, em entrevista realizada ao final do período de observaçóes:

A gente começa na alfabetização com as vogais. Você introduz as vogais pras crianças, através de quê? As vogais eu colo num cartãozinho com as letras, com música. Depois que elas memorizaram bem as vogais, aí nós partimos pras consoantes. Aí a gente trabalha o quê? Cada letra do alfabeto, que juntando uma consoante com uma vogal, ele consegue formar uma sílaba, através de textos daquela letrinha do alfabeto que você tá trabalhando. A antiga família né? A família silábica. Porque agora você náo pode mais trabalhar o ba- be- bi- bo- bu-; só que você trabalha de outra forma, não com aquela decoração da criança, através de cartilhas, mas através "dela" perceber essas sílabas, num texto, num trava-língua, em parlenda.

De fato, observamos que as vogais foram inicialmente "apresentadas” para as crianças. As consoantes, também, depois, uma a uma, na sequência do alfabeto. Como forma de auxiliar os alunos na memorização das vogais, diariamente a professora cantava uma música das 
vogais. Depois que a letra foi devidamente apresentada à criança, seguiase a sequência de atividades com foco no grupo silábico em questão:

- cruzadinhas;

- $\quad$ caça-palavras;

- $\quad$ formação de palavras a partir de sílabas;

- completar palavras com letras ou sílabas faltosas, recorte e colagem de letras e palavras;

- $\quad$ ditados;

- $\quad$ separação de palavras em sílabas;

- cópia e leitura de textos acartilhados.

Durante os meses que estivemos na turma, percebemos que para cada letra trabalhada eram utilizadas em torno de cinco a seis atividades mimeografadas de caráter repetitivo.

$\mathrm{Na}$ mesma entrevista realizada ao final do ano, indagamos a professora sobre a opção pelas cruzadinhas e caça-palavras. Ela explicou:

Porque eles se interessam, eles adoram um caça-palavra, uma cruzadinha. E eu, na minha percepção, acho que dá assim mais certo. Eu acho que a criança, no caça-palavras, mesmo aquela criança que ainda não estava alfabetizada, ela consegue "tá" desenvolvendo o caça-palavra.

Depois dessas atividades, era costume da professora reescrever algumas palavras no quadro e fazer com os alunos uma retomada daquele grupo silábico, com uma lista de palavras do "G", por exemplo. Depois do registro, os alunos eram convidados a fazer, coletivamente, a leitura das palavras. A professora ia marcando um traço debaixo das sílabas de cada palavra e os alunos soletrando, sílaba por sílaba, em voz alta.

A partir do segundo semestre, a professora começou a desenvolver mais uma atividade, no conjunto do trabalho com determinada 
letra do alfabeto. A cópia de um texto curto seguida por uma leitura controlada. Ela solicitava a leitura silenciosa dos alunos: "Vocês já sabem juntar os pedacinhos... têm que pensar na cabecinha! Uma consoante e uma vogal”. E depois, lia com eles, marcando no quadro sílaba por sílaba. Sobre essa atividade, a professora afirmou:

Porque aquilo que você copia você memoriza mais. [...] E pra que aqueles que náo conseguiam ler sozinhos, com a minha ajuda e com a ajuda dos colegas, eles se habituariam a ler também. Muitos chegaram ao final do ano lendo, a maioria.

O livro didático adotado pela escola aparecia em segundo plano. Nas palavras da própria professora, o livro é "para ser feito em casa, porque as atividades propostas não têm uma sequência. O livro eu dava como se fosse uma revisão do que tinha dado em sala de aula".

Observamos que em sala de aula o livro didático foi utilizado pouquíssimas vezes e as sequências didáticas que os autores propunham, em torno de um gênero textual, não eram exploradas de maneira integral. A professora selecionava aleatoriamente as páginas que seriam trabalhadas com a turma. Como ela mesma confirma, o livro foi usado mais vezes como tarefa de casa. A professora o avalia de modo positivo, mas parece que ele não comporta a lógica que ela enxerga sobre processos de ensino e aprendizagem da leitura e da escrita. Para ela, a repetição é necessária para o aprendizado. Fazer diversas atividades envolvendo o mesmo conteúdo, no seu entendimento, é uma opção para que os alunos construam o conhecimento.

Diante das observaçóes que realizamos, compreendemos que não eram muitos os recursos pedagógicos utilizados por essa professora. A lousa e uma folha com uma atividade impressa eram suficientes para que desenvolvesse o trabalho. Assim, como não eram variados os textos que ela utilizava, a maioria provinha de coleçóes para alfabetizar e eram, em grande parte, do tipo acartilhados. 
Buscando refletir sobre as estratégias e concepções confirmadas na fala da própria docente, observamos que essas incluem a apresentação dos diferentes tipos de letra e das famílias silábicas, atividades de memorização e a leitura coletiva, sílaba por sílaba.

Outra consideração importante refere-se aos textos utilizados pela professora. Ainda que em um dado momento ela mencione os gêneros textuais trava-línguas e parlendas, durante as aulas, observamos poucas situaçóes nas quais textos dessa natureza apareceram, predominando os que têm sido considerados "acartilhados", com pouco ou nenhum significado para as crianças. A opção por cruzadinhas e caça-palavras, que poderia indicar um trabalho com textos de circulaçáo social, está vinculada à ideia de aquisição do sistema de escrita, ao trabalho com as unidades menores da palavra escrita. Em nenhum momento a professora dá indícios de que se utilizava desses textos para uma aproximação com práticas reais de uso da leitura e da escrita.

Nessa turma, o texto é utilizado apenas como pretexto para o ensino sistemático da escrita. Os alunos leem textos curtos, que às vezes já sabem de memória, ou a letra de uma música infantil, ou ainda textos inadequadamente escolarizados, no sentido apontado por Soares (1999), para identificarem letras ou palavras de um determinado grupo silábico. Náo observamos uma preocupação com a variedade de gêneros textuais defendida pelos pesquisadores da alfabetização na perspectiva do letramento, como Soares (1996), Macedo (2001), entre outros.

Esses pesquisadores defendem que a escola, responsável pelo ensino da leitura e da escrita, deveria reduzir as diferenças sociais existentes entre as crianças que têm acesso à leitura desde muito cedo e as que não participam de uma cultura letrada. Essa reduçáo só aconteceria por meio da vivência diária de práticas reais de leitura e produção de textos diversificados, situaçóes não observadas nessa sala de aula.

Para essa professora, o exercício de copiar repetidas vezes ainda é um caminho que pode contribuir com a aprendizagem dos alunos de seis anos. Ao copiarem palavras ou textos com predominância de vocábulos de uma mesma "família", os alunos estariam fazendo um exercício de memorização do grupo estudado. Os dados indicam a opção pelo trabalho sistemático com o foco restrito na codificação e decodificação 
de palavras, mesmo a professora afirmando partir de um texto. A opção metodológica dessa professora é por métodos sintéticos, nos quais as atividades de ensino são centradas nas partes que compóem as palavras, como as sílabas e as letras, com forte apelo à memorização, em detrimento de uma metodologia que contemple, de fato, os usos e as funçôes sociais dos textos escritos. Consideramos que, na concepção de alfabetização presente nessa prática, a escrita é vista como um código de transcrição das unidades sonoras em unidades gráficas.

A complexidade que envolve o processo de alfabetização tem se tornado um desafio para docentes que atuam com turmas de crianças de seis, sete e oito anos. Acreditamos que, para uma prática alfabetizadora mais adequada, é necessário que o professor tenha conhecimento teórico sobre:

- $\quad$ linguagem escrita e oral;

- $\quad$ as formas pelas quais as crianças se apropriam da natureza alfabética do sistema de escrita;

- a relação entre alfabetização e letramento nos termos tratados pelos Novos Estudos sobre Letramento (STREET, 1984).

Todos esses aspectos revelam que o ponto de partida da professora para ensinar a leitura e a escrita foram as letras do alfabeto, reduzindo a experiência das crianças de seis anos ao contato com uma língua abstrata, supostamente neutra e ensinada a partir de técnicas de memorização da relação fonema-grafema.

\section{ESCOLA 2: TEXTO E CONTEXTO COMO PONTOS DE PARTIDA PARA O ENSINO DA LEITURA E DA ESCRITA}

A escola 2, localizada na zona oeste de Juiz de Fora, atende crianças das comunidades do entorno e funciona em um prédio que pertence à Universidade Federal de Juiz de Fora (UFJF) cedido à Prefeitura em 1967. No início da pesquisa, a turma era composta por 22 crianças, sendo 9 meninas e 13 meninos, e, no final, por 23 crianças, sendo 9 meninas e 14 meninos. O espaço da sala de aula era amplo, organizado com cartazes fixos (ajudantes, 
aniversariantes, calendário, numerais e alfabeto). Possuía um quadro no qual eram afixados cartazes sobre as atividades que estavam sendo desenvolvidas pela turma, uma mesa comprida, com potes de jogos na parte debaixo; acima, uma caixa de "achados e perdidos", um suporte com o aparelho de som, uma casinha de brinquedos. Havia 25 mesas individuais com cadeiras, na altura adequada para tal faixa etária, organizadas em duplas, formando três fileiras com oito mesas cada uma, de frente para o quadro.

Após as observações e a entrevista com a professora, foi possível perceber que esta aproveitou diferentes situaçóes para desenvolver sua prática de alfabetização, explorando distintos contextos e recursos presentes na escola, como livros literários, poemas e atividades propostas nos livros didáticos para, a partir deles, desenvolver atividades relacionadas à apropriação do sistema de escrita alfabética.

Outro aspecto a ser destacado é o encadeamento das atividades realizadas a partir de um determinado texto ou contexto, o que demonstra uma preocupação com a continuidade do trabalho pedagógico, estabelecendo interligaçóes entre as atividades realizadas em sala de aula. Tais atividades foram organizadas a partir de determinados textos, ora tendo o próprio texto como objeto de ensino, ora como estratégia de mediação para o ensino de outros conteúdos.

O planejamento das aulas com base em um livro literário é um tipo de prática que foi descrito pela professora na entrevista inicial, quando relatou como planeja as suas aulas. Ela destacou ainda que é a partir da história do livro que seleciona as letras e palavras que trabalhará, não seguindo a sequência do alfabeto:

[...] normalmente, eu gosto de ver alguma coisa na sala que tá precisando. Entâo, vamos dizer, a gente tá com problema de relacionamento, tá havendo um pouco de agressividade, aí eu vou atrás de um livro de literatura que tenha aquilo, que tenha aquele tema. Agora, vamos dizer: Matemática. Ih... Ah... Tá na hora da gente começar a trabalhar conjuntos, coleçôes, lá vou eu na literatura. Entáo, eu sempre procuro na literatura alguma coisa relacionada com a sala de aula. [...] Entâo, ali eu já vou tirando as letras que eu já vou trabalhar. (Entrevista realizada em 06/02/2013) 
Durante a pesquisa foram utilizados dois livros literários para o desencadeamento das atividades: $A$ descoberta da joaninha e Tião carga pesada. Analisaremos aqui o trabalho desenvolvido com o segundo livro.

A partir da história do livro Tião Carga Pesada, a professora trabalhou o tema amizade com base nas atitudes dos personagens, promoveu reflexões sobre essas atitudes, solicitou às crianças que conversassem com seus familiares a respeito do que é amizade, conversou com as crianças na rodinha sobre o que os familiares disseram, e perguntou para elas o que é um amigo de verdade. As respostas obtidas foram anotadas e depois usadas na elaboração de um mural sobre o tema, no qual também foram colocados os desenhos que as crianças produziram. A professora ainda apresentou outro livro literário sobre o tema, tanto na versão impressa quanto na digital.

Em outras atividades, o livro foi tomado como próprio objeto de ensino, como na aula em que a professora trouxe mais exemplares e as crianças puderam manuseá-lo, acompanhando o texto em seu suporte original, explorando os elementos que o constituem (capa, ilustraçóes, lista de distribuição), além da compreensão da história e do significado de palavras e expressóes. Também aproveitou o tema coleçóes apresentado na história para desencadear algumas atividades.

Para trabalhar com o sistema de escrita, a professora utilizou a escrita dos nomes dos personagens, dos objetos das coleçóes da história e das coleçóes apresentadas pelas crianças. Enfatizava todas as formaçóes silábicas da palavra e não apenas a sílaba inicial, explorando as sílabas canônicas e não canônicas e também as "dificuldades ortográficas", como na escrita da palavra folha:

[...] Diz a palavra folha, pede para escutarem o som e diz a primeira sílaba, enfatizando o som da letra "F". As crianças dizem: "F com O"; "F com U"; "F com $\mathrm{O}$ ". A professora confirma que é " $\mathrm{F}$ com O" e escreve no quadro. Pede às crianças que já sabem ler para não falarem, pois senão os outros colegas não vão ter a chance de responder. Pede para essas crianças escreverem as palavras sozinhas e depois conferir com a que a professora escreveu. Fala a sílaba "LHA". 
Algumas crianças dizem que é a letra "L", uma menina diz que é o "L com A". A professora diz que é quase isso, mas se colocar só o "L com A" vai formar "LA" (algumas crianças falam junto com a professora) e a palavra vai ficar" "FOLA". Explica que tem uma letrinha entre o "L" e o "A", para fazer o som do "LHA". Algumas crianças dizem que é a letra "I". [...]. (Anotaçôes do diário de campo, dia 09/05/2013)

Percebemos, assim, que é a partir da escrita de palavras retiradas do texto/contexto trabalhado que a professora promove a reflexão e o trabalho com os aspectos formais do sistema de escrita, tornando essa aprendizagem mais significativa para a criança, como relatado por ela na entrevista.

Outra prática que merece destaque refere-se à proposta de escolha do nome da biblioteca da escola, na qual houve a realizaçáo de um sarau com os poemas de Vinícius de Moraes. As crianças dos primeiros anos ensaiaram alguns poemas desse autor e a professora trabalhou com o poema $A$ foca em sala de aula.

Ela explorou o poema escrito numa folha, pediu para encontrarem o título e circularem, acharem o nome do autor e colorirem, explicou sobre as rimas, leu cada estrofe e, junto com as crianças, identificou as palavras que rimavam, trabalhando assim com um dos elementos característicos de textos poéticos. Também propôs a elaboração de novas estrofes para o poema, observando a formação de novas rimas. Após escolherem oralmente as estrofes, ao escrevê-las, ensinava sobre a organização dos versos. Consideramos que, nessas atividades, o poema foi utilizado como objeto de ensino, pois foram explorados os seus elementos, como título, autor, as rimas em cada estrofe e sua organização estrutural.

Em outras atividades, a professora explorou a leitura do poema, enfatizando a identificação de palavras como boca, foca, no, ficar, seu e briga, e a escrita de outras (foca, bola, nariz, sardinha), utilizando o texto para desenvolver atividades voltadas para a apropriação do sistema de escrita. Ao propor a escrita dessas palavras, e também quando escreviam as novas estrofes, a professora enfatizava o reconhecimento dos sons de todos os fonemas que formavam a palavra. Para ela o reconhecimento dos fonemas é fundamental para que as crianças aprendam a ler e a escre- 
ver; e sempre chamava a atenção para essa questão, sendo recorrente em sua fala em sala de aula, em muitos dos momentos observados, como no dia 05/03/2013: "Para aprender a ler e escrever, a gente tem que começar assim, olha: fazendo o barulhinho das letras". Assim, nesse trabalho com o poema, a professora partiu de um contexto da escola, utilizou o texto como objeto de ensino e também como instrumento para o trabalho com a alfabetização.

Outro ponto importante foi a utilização dos conteúdos do livro didático de Matemática para o desenvolvimento de atividades voltadas para a alfabetização. Mesmo que o objetivo fosse trabalhar determinados conceitos ou quantidades, a professora explorava os contextos em que tais atividades eram propostas. Por exemplo, para estudar a quantidade e o numeral um, havia um poema: a professora conversou com as crianças sobre o que dizia o texto; para trabalhar a quantidade e o numeral sete, havia uma cena da história da Branca de Neve e os sete anóes, e ela explorou oralmente o nome dos anóes, descrevendo suas características; e para trabalhar o numeral e a quantidade oito, havia a figura dos planetas no sistema solar, explicou-lhes sobre a mudança no número de planetas e, assim, conversaram sobre o tema; ou quando explorou a escrita das palavras "dentro" e "fora" em uma tabela para que as crianças compreendessem como fazer a atividade.

Também percebemos um trabalho sistemático com o alfabeto, nem sempre com base em um texto, um dos pontos de aproximação com a prática da professora da escola 1 . Nos primeiros dias de observação, a professora trabalhou a música $A B C$ da Mônica para explorar o alfabeto, além de lê-lo na sala nesses dias. No segundo dia de observaçáo, realizou uma atividade para diferenciar letras e numerais, refletindo sobre o uso de cada um deles, a partir do que as próprias crianças relatavam. Para o ensino do alfabeto, também utilizou diferentes jogos, a maioria deles nas aulas de informática e alguns por ela confeccionados e utilizados na sala de aula.

Ainda com o foco no alfabeto, a professora desenvolveu uma atividade de separação entre vogais e consoantes. Logo após explorar a música do $A B C$ da Mônica, ela falou sobre as "cinco letrinhas especiais do alfabeto" e trabalhou com a música $A, E, I, O, U$, do Patati Patatá. A partir dessa música, elaborou um álbum de figurinhas das vogais, no qual as crianças deveriam colar as figuras de acordo com a vogal inicial. 
Esta característica dos métodos sintéticos de alfabetização presente na prática da professora foi comentada por ela numa das entrevistas, como se observa abaixo:

Então, eu acho que o primeiro passo teria que ser as vogais mesmo. Porque as vogais aparecem em todas as palavras. (Entrevista realizada em 08/11/2013)

Segundo a professora, depois que as crianças reconhecem os sons das vogais, fica mais fácil trabalhar com os outros fonemas, ou seja, com as consoantes. Nesse sentido, observa-se aqui uma perspectiva conflitante com a proposta metodológica na qual o texto é tomado como objeto central para o ensino da língua escrita, presente na maior parte das aulas observadas, uma vez que as unidades menores da língua (letras, sílabas e palavras) eram tratadas a partir dos textos em circulação na sala de aula, sem uma preocupação com a sequenciação do alfabeto.

Um aspecto que predominou durante as observaçóes foi em relação à proposta de escrita das palavras, sendo a maioria delas relacionadas ao contexto/texto estudado. Para explicar a escolha dessas palavras, a professora afirmou que, por trabalhar com o nome das crianças, considera que já está “[...] trabalhando praticamente com o alfabeto todo" e, assim, sente "[...] liberdade para trabalhar com qualquer palavra".

Sendo essas palavras retiradas desse contexto, não apresentavam uma sequência rígida de trabalho com determinados tipos de palavras por exemplo, somente palavras com sílabas canônicas ou que iniciam com determinada letra ou família silábica. As palavras são trabalhadas explorando-se todas as formaçóes silábicas que as compóem. Percebemos também que as propostas de produção escrita traziam para as crianças a dimensáo de texto relacionado a um contexto, como a escrita do convite para o aniversário do palhaço Pipoca, a escrita de um comentário em um blog, da parlenda dos dedos e sobre o passeio do palhaço Pipoca.

Em uma perspectiva diferente, o que observamos foi uma prática de alfabetização que priorizou o trabalho com o sistema de escrita alfabética, tendo uma forte ênfase no reconhecimento de fonemas, mas que foi desenvolvida a partir de determinados contextos pedagógi- 
cos construídos para esse trabalho, elaborados a partir de determinados textos ou situaçóes vivenciadas na escola, procurando, assim, tornar a aprendizagem da leitura e da escrita significativa para a criança.

\section{CONSIDERAÇÕES FINAIS}

Nossos dados indicam que o trabalho pedagógico nas duas salas de aula observadas é centrado na alfabetização compreendida como a apropriação do sistema de escrita (SOARES, 1996).

Contrastando os dados das duas turmas, observamos semelhanças e diferenças na forma como o processo de alfabetização foi mediado pelas professoras. $\mathrm{Na}$ escola 1 , a alfabetização ocorreu apenas nas aulas de Português, ao passo que na escola 2 todas as atividades das diferentes áreas do currículo eram aproveitadas para o ensino e a aprendizagem da língua escrita.

Ambas as professoras tinham como objetivo central no trabalho com crianças de seis anos a compreensão do sistema de escrita alfabética. A professora 1 organizava sua prática a partir da sequência do alfabeto e das famílias silábicas, utilizando-se claramente do que nomeamos métodos sintéticos de alfabetização. A professora da escola 2 priorizava o trabalho com o sistema de escrita a partir de textos em circulação na sala de aula, embora não abrisse mão do trabalho sistemático com vogais e consoantes. Ambas as professoras iniciaram o trabalho com o reconhecimento das vogais, o que é uma forma de trabalho tradicional, característica do início da alfabetização.

Nos estudos sobre a Psicogênese da Língua Escrita (FERREIRO; TEBEROSKY, 1986), Goulart (2010) e Smolka (1988), entre outros, evidenciam que as crianças aprendem a partir dos sentidos construídos na elaboração conceitual da escrita e não por atividades de repetição. Pesquisas sobre práticas com crianças de seis anos evidenciam a importância do lúdico e do trabalho contextualizados com a escrita no desenvolvimento de uma alfabetização mais significativa (GOULART; SOUZA, 2015; BRANDÃO; ROSA, 2010). É necessário que a criança compreenda a escrita como um modo particular de representação da linguagem, ou seja, que entenda a natureza do sistema de escrita a partir dos sentidos construídos em situaçóes reais de contato com textos de circulação social, em uma perspectiva de letrar alfabetizando como 
propõe Goulart (2010). A professora da escola 1 praticamente não se utilizou de textos autênticos para a alfabetização. A professora $2 \mathrm{o}$ fez, priorizando os textos literários. Além de usá-los como referência para o ensino do sistema de escrita, observamos que havia uma preocupação com o letramento literário das crianças (COSSON, 2012; PAIVA; RODRIGUES, 2008) na medida em que diferentes atividades de fruição foram observadas, como:

- $\quad$ o sarau com a poesia de Vinícius de Morais;

- $\quad$ o acesso e a discussão de textos autênticos;

- $\quad$ os livros de literatura infantil;

- a escolha do nome da biblioteca da escola;

- $\quad$ o uso da biblioteca para a escolha de livros.

O livro didático de alfabetização não foi uma referência para a organização das práticas de ensino das duas professoras, tendo sido mais utilizado para atividades de casa. Assim, nenhuma delas seguiu a sequência proposta pelo livro.

Por fim, cabe destacar o quanto essas práticas desenvolvidas com as crianças de seis anos ainda se distanciam do que propóem as Referências Curriculares Nacionais para a Educação Infantil no que tange à importância do trabalho com as múltiplas linguagens, a necessidade de se priorizar o lúdico e a brincadeira nos processos de construçáo do conhecimento das crianças, pressupostos defendidos por estudiosos da infância (KRAMMER, 1992; WAJSKOP, 1995). As práticas em questão priorizam o trabalho exaustivo com a linguagem verbal, com o sistema de escrita reduzindo a formação da criança a esse objeto de conhecimento, como observado na prática da professora 1. Assim, a pesquisa nos indica que as crianças de seis anos estão submetidas às mesmas práticas que sempre nortearam os anos iniciais do EF, cujo foco predominante é o trabalho com a linguagem verbal em detrimento de outras linguagens, como a artística, a visual, a dança, a música, tão importantes na formação da criança. Sob os professores recaem as mais diferentes pressóes, especialmente aquelas relacionadas às avaliaçóes externas que esperam que as crianças dos anos iniciais se alfabetizem até os 8 anos de idade (CARVALHO; MACEDO, 2010). 


\section{REFERÊNCIAS}

BAKHTIN, M. (V. N. VOLOCHÍNOV). Marxismo e Filosofia da Linguagem. São Paulo: Hucitec, 1995.

BRANDÁO, A.C.P.; ROSA, E.C.S. (orgs.). Ler e escrever na educação infantil. Belo Horizonte: Autêntica, 2010.

BRASIL. Presidência da República. Casa Civil. Subchefia para Assuntos Jurídicos. Lei ${ }^{\circ} 11.274$, de 6 de fevereiro de 2006. Altera a redação dos artigos 29, 30, 32 e 87 da Lei no 9.394 de 20 de dezembro de 1996, que estabelece as diretrizes e bases da educação nacional, dispondo sobre a duração de 9 (nove) anos para o ensino fundamental, com matrícula obrigatória a partir dos 6 (seis) anos de idade. Brasília, DF, 6 fev. 2006b. Disponível em: <http://www.planalto.gov.br/ ccivil 03/ ato2004 2006/2006/lei/l11274.htm>. Acesso em: 30 mar. 2012.

CASTANHEIRA, M.L.; DIXON, CN.; GREEN, J.L. Práticas de letramento em sala de aula: uma análise de açóes letradas como construção social. Revista Portuguesa de Educação, Portugal, v. 20, n. 2, p. 7-38, 2007.

CARVALHO, G.F.S.; MACEDO, M.S.A.N. Avaliação oficial: o que dizem os mediadores da política pública sobre o impacto na prática docente. Estudos em Avaliação Educacional, São Paulo, v. 21, n. 46, p. 253-270, maio-ago. 2010.

COSSON, R. Letramento literário: teoria e prática. 5a ed. São Paulo: Contexto, 2012. EZPELETA, J.; ROCKWELL, E. Pesquisa participante. Trad. por Francisco Salatiel de Alencar Barbosa. São Paulo: Cortez: Autores Associados, 1989, p. 31-54.

FERREIRO, E.; TEBEROSKY, A. A psicogênese da lingua escrita. Porto Alegre: Artes Médicas, 1986.

GOULART, C. Cultura escrita e escolar: letrar alfabetizando. In: MARINHO, M.; CARVALHO, G. Cultura escrita e letramento. Belo Horizonte: Editora da UFMG, 2010.

GOULART, C.M.A.; SOUZA, M. Como alfabetizar? Na roda com professoras dos anos iniciais. São Paulo: Papirus, 2015.

GREEN, J; DIXON, C.N.; ZAHARLICH, A. A etnografia como uma lógica de investigação. Educação em Revista, Belo Horizonte, v. 42, p. 13-79, dez. 2005.

KRAMER, S. A política do pré-escolar no Brasil: a arte do disfarce. São Paulo: Cortez. 1992. 
MACEDO, M.S.A.N. Desafios da alfabetização na perspectiva do letramento. Presença Pedagógica, Belo Horizonte, v. 7, p. 17-23, 2001. - Interaçóes nas práticas de letramento em sala de aula: o uso do livro didático e da metodologia de projetos. São Paulo: Martins Fontes, 2005.

PAIVA, A.; RODRIGUES, P.C.A. Letramento literário na sala de aula: desafios e possibilidades. In: CASTANHEIRA, M.L.; MACIEL, F.I.P; MARTINS, R.M.F. (Orgs.). Alfabetização e letramento na sala de aula. Belo Horizonte: Autêntica, 2008.

ROCKWELL, E. La experiencia etnográfica: historia y cultura en los procesos educativos. Buenos Aires: Paidós, 2009, p. 17-39.

SMOLKA, A.L. A criança na fase inicial da escrita. A alfabetização como um processo discursivo. São Paulo: Cortez, 1988.

STREET, B.V. Literacy in Theory and Practice. Cambridge: Cambridge University Press, 1984.

STREET, B.V.; HEATH, S. On ethnography. New York and London: Columbia University Press, 2008.

SOARES, M. A escolarização da literatura infantil e juvenil. In: EVANGELISTA, A.; BRANDÃO, H.B.; MACHADO, M.Z.V. A escolarização da leitura literária. Belo Horizonte: Autêntica, 1999.

. Letramento: um tema em três gêneros. Belo Horizonte: Autêntica, 1996.

WAJSKOP, G. O brincar na Educação Infantil. Cadernos de Pesquisa. São Paulo, n. 92, p. 62-69, fev.1995.

Recebido em 14 de janeiro de 2017. Aprovado em 24 de junho de 2017. 